D. Craciun et al. / Applied Surface Science 336 (2015) 391-395

\title{
Mechanical properties of pulsed laser deposited nanocrystalline SiC films
}

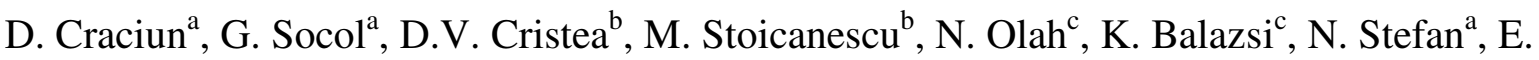 \\ Lambers $^{\mathrm{d}}$, V. Craciun ${ }^{\mathrm{a}},{ }^{*}$ \\ ${ }^{\mathrm{a}}$ National Institute for Laser, Plasma, and Radiation Physics, Magurele, Romania \\ ${ }^{\mathrm{b}}$ Transilvania University, Brasov, \\ ${ }^{\mathrm{c}}$ RomaniacInstitute for Technical Physics and Materials Science, Budapest, Hungary \\ ${ }^{\mathrm{d}}$ Major Analytical Instrumentation Center, University of Florida, Gainesville, FL 32611, USA
}

\begin{abstract}
The mechanical properties of nanocrystalline $\mathrm{SiC}$ thin films grown on (100) $\mathrm{Si}$ at a substrate temperature of $1000^{\circ} \mathrm{C}$ under a $\mathrm{CH} 4$ atmosphere using the pulsed laser deposition (PLD) technique were investigated.Nanoindentation results showed that films exhibited hardness values around $36 \mathrm{GPa}$ and Young modulusvalues around $250 \mathrm{GPa}$. Scratch tests found that films were adherent to the substrate, with critical loadvalues similar to those recorded for other hard coatings deposited on significantly softer Si substrates. Wear tests performed at a temperature of $900^{\circ} \mathrm{C}$ showed that films exhibited friction coefficients andwear rates very similar to those measured at room temperature, due to the presence of $\mathrm{C}-\mathrm{C}$ bonds asevidenced by X-ray photoelectron spectroscopy investigations. These results recommend such coatingsfor demanding high temperature applications such as nuclear fuel encapsulation.
\end{abstract}

\section{Introduction}

Due to its excellent mechanical, optical, thermochemical,electronic and electrical properties $\mathrm{SiC}$ has been extensively inves-tigated for potential uses in microelectronics [1,2], hard andprotective coatings for tools [3,4], water splitting [5] and bio-applications [6]. More recently, it has been suggested that due toits very low neutron absorption cross section, $\mathrm{SiC}$ could be used inthe nuclear industry as encapsulating coatings for nuclear fuel innext generation reactors [7,8]. For such applications the depositedSiC films are expected to maintain their properties at temperaturesbetween 500 and $800^{\circ} \mathrm{C}$ and even higher, up to $1000^{\circ} \mathrm{C}$, in the caseof an emergency if an accident occurs. The deposition of high quality $\mathrm{SiC}$ films to study their proper-ties is a challenging process due to their low sputtering yield, highmelting temperature and reactivity with oxygen [1-4]. Progresshas been recently made using CVD, ion beam or sputtering tech-niques [1-8]. By using the Pulsed Laser Deposition (PLD) technique, good quality $\mathrm{SiC}$ films that are very useful for properties investiga-tions were also synthesized [9-14]. The use of a high laser fluence, a very low residual vacuum, high purity $\mathrm{CH} 4$ and high repetitionrates were necessary to grow the films [15]. Results obtained fromsimulations of the X-ray reflectivity curves acquired from the PLDgrown films showed that they possess a low surface roughness (rmsvalues $<1 \mathrm{~nm}$ ) and a density around $3.20 \mathrm{~g} / \mathrm{cm} 3$, almost identical tothe tabulated value for bulk SiC. Grazing incidence X-ray diffractionstudies showed the films were nanocrystalline while X-ray photo-electron 
spectroscopy investigations found that films contained inbulk a rather low oxygen concentration, below 2-3 at.\%. The resultsof systematic nanoindentation investigations and wear tests per-formed at room temperature and $900{ }^{\circ} \mathrm{C}$ on PLD grown SiC films arepresented below.2. Experimental detailsThe PLD experimental set up used to deposit films has beendescribed previously [15]. It uses a KrF excimer laser $\left(_{-}=248 \mathrm{~nm}\right.$,pulse duration ${ }_{-}=25$ $\mathrm{ns}, 8 \mathrm{~J} / \mathrm{cm} 2$ fluence, $40 \mathrm{~Hz}$ repetition rate)to ablate $\mathrm{SiC}$ polycrystalline targets (Angstrom Sciences) in astainless steel chamber. The ultimate pressure in the deposi-tion chamber was in the low 10-6Pa. Since the properties ofthe deposited films improved with the increase of the substratetemperature, we restricted our investigations to films depositedusing the maximum temperature of $1000^{\circ} \mathrm{C}$ achievable in our deposition system. Moreover, because the wear testing of suchfilms involved experiments at $900^{\circ} \mathrm{C}$, it was not very useful todeposit them at lower temperatures. Series of films were depositedat $1000^{\circ} \mathrm{C}$ on $\mathrm{Si}$ substrates (MEMC Electronic Materials, Inc.)for 27,000 and 14,000 pulses (generic names $\mathrm{SiC} 17$ and $\mathrm{SiC}$ 18,respectively) under a high purity of $2 \times 10-5 \mathrm{mbar}$ of $\mathrm{CH} 4$. After deposition, films underwent a $1 \mathrm{~h}$ anneal at the deposition temper-ature and then were slowly cooled at room temperature at a rateof $5 \circ \mathrm{C} / \mathrm{min}$. As mentioned in the Introduction part, the crystallinestructure, surface roughness, mass density, elemental composi-tion, and optical properties of these films were previously reported[15]. According to ellipsometry measurements, the thickness ofthe deposited films were around $1 \_\mathrm{m}$ and $0.5 \_\mathrm{m}, \pm 5 \%$ on anarea of $2 \mathrm{~cm} 2$ for the $\mathrm{SiC} 17$ and $\mathrm{SiC} 18$ series of samples, respec-tively.The mechanical properties of the thin films were investigatedusing a nanoindentation device produced by CSM Instruments(NHT-2) equipped with a Berkovich diamond tip. To minimize sub-strate contributions, the indentation experiments were performedcontrolling the depth penetration of the indenter, between 80 and120 $\mathrm{nm}$ and 40 and $150 \mathrm{~nm}$ at maximum loads ranging from $\sim 4$ to $7 \mathrm{mN}$ and $\sim 1$ to $\sim 11 \mathrm{mN}$ for samples $\mathrm{SiC} 17$ and samples $\mathrm{SiC} 18$,respectively. The hardness and reduced modulus were determinedfollowing the model of Oliver and Pharr [16]. On each series of sam-ples, a matrix of measurements, with $\mathrm{X}$ and $\mathrm{Y}$ displacements of0.05 $\mathrm{mm}$, have been made, with the following protocol: linear load-ing, loading rate $=100 \mathrm{~nm} / \mathrm{min}$, pause during full load $2 \mathrm{~s}$ (in orderto minimize the creep effect), and unloading rate $=100$ $\mathrm{nm} /$ min.Considering the thickness variation of PLD grown films only theindentations that were located on the central area of the filmswere taken into consideration. The load resolution of the appara-tus is $40 \mathrm{nN}$, with a usable indentation load range between 0.1 and500 $\mathrm{mN}$. The thermal drift, which can influence the measurementswith indentation depths lower than 100 $\mathrm{nm}$, is countered with theuse of a zirconium reference ring, which is in contact with thesample surface. The reference ring also acts as a local environmen-tal enclosure to passively protect the measurement location fromair currents, sound waves and changes in humidity and temperature. Furthermore the environmental temperature and humidityare kept constant during measurement sessions. For comparisonpurposes, nanoindentation measurements were performed on thesilicon substrate, with the following protocol: Berkovich diamondindenter, linear loading, $300 \mathrm{~nm}$ penetration depth, loading andunloading rates of $1000 \mathrm{~nm} / \mathrm{min}$. The scratch tests were performed on a Micro Scratch Tester (CSMInstruments) using a 100Cr6 steel tipped indenter with a Rockwellgeometry (tip radius $=100 \_\mathrm{m}$ ). The load was applied progressively,from $0.03 \mathrm{~N}$ to $9 \mathrm{~N}$ for samples $\mathrm{SiC} 17$, and from 0.03 to $8 \mathrm{~N}$ for sam-ples $\mathrm{SiC}$ 18 , with a speed of $1 \mathrm{~N} / \mathrm{min}$. The length of the tests wasset at $3 \mathrm{~mm}$, being confined to the samples' area of relatively uni-form thickness. Three tracks were made on each measured sample,with a displacement on the $\mathrm{Y}$ axis of $0.2 \mathrm{~mm}$ between each track. The critical load values were obtained after optical analysis of the wear tracks, and these are defined as follows: Lc1- the load neces-sary for the emergence of the first cracks in the film; Lc2- the loadcorresponding to the first delamination of the film; Lc3- the loadresponsible for the delamination of more than $50 \%$ of the film fromthe wear track. Mechanical wear tests were 
carried out at $25^{\circ} \mathrm{Cand} 900^{\circ} \mathrm{C}$ in air atmosphere using a dry ball-on-disk tribometerfrom CSM Instruments. The bearing balls were made out of Si3N4having a diameter of $5 \mathrm{~mm}$. The normal load was set at $1.00 \mathrm{~N}$, themaximum linear speed at $0.05 \mathrm{~m} / \mathrm{s}$ and the stop condition at 2400cycles. The chemical composition of the films was investigated byX-ray photoelectron spectroscopy (XPS) on a Physical Electron-ics PHI 5000 VersaProbe II using monochromatic Al K_radiation (1486.6 eV). Sputtering of the surface was done with $2 \mathrm{kV}$ Ar ionswhile the sample was rotated to ensure a uniform removal rate.

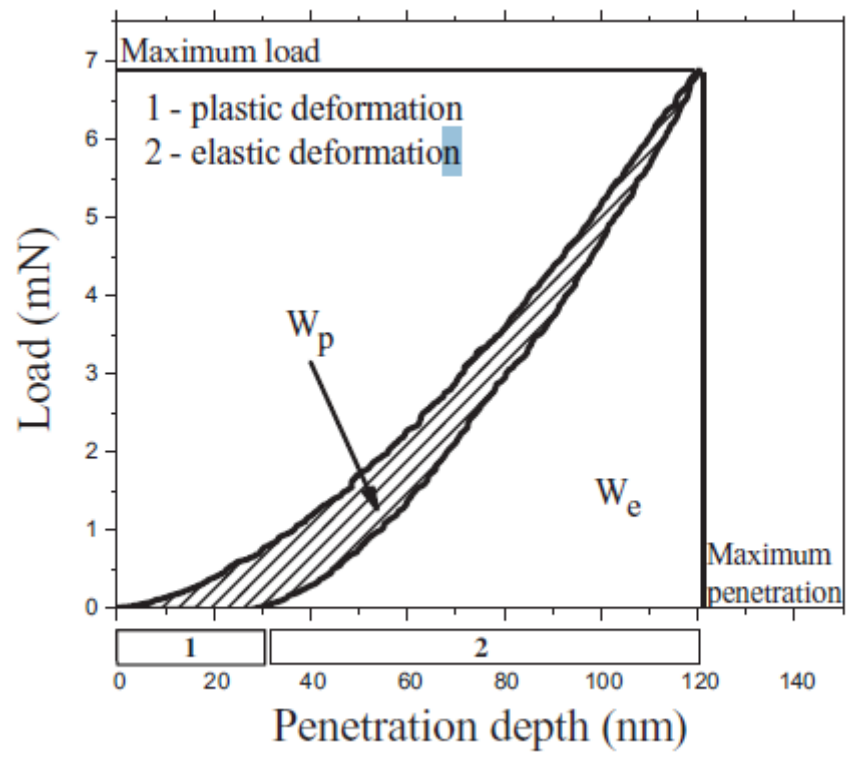

Fig. 1. Loading-unloading curves for a penetration depth of $120 \mathrm{~nm}$ recorded for asample $\mathrm{SiC} 17$.

\section{Results and discussion}

Nanoindentation measurements were performed in multiple locations on several samples, with different penetration depths. The representative results are presented in Table 1. Overall, the results showed that the films were very hard, exhibiting values from $\sim 32$ to $\sim 41 \mathrm{GPa}$ for both samples, while the elastic mod-ulus values were around 250-260 GPa, typical values for goodquality $\mathrm{SiC}$ films $[17,18]$. However, upon further investigation of the data, several observations can be extracted. Fig. 1 represents a typical loading-unloading curve for a penetration depthof $120 \mathrm{~nm}$ recorded for sample SiC 17. From the evolution of the loadingunloading curves, it can be observed that the film exhibiteda very small degree of plastic deformation. A similar evolution was noticed for the remaining measurements, regardless of the penetration depth, which leads to the conclusion that the mechanicalcharacteristics are relatively homogeneous throughout the mea-sured thickness of the films. This observation can be supportedby a more in-depth analysis of the loading-unloading curves. By analyzing the load-displacement response, one can extract other mechanical metrics apart from the hardness $\left(\mathrm{H}_{\mathrm{it}}\right)$, such as the plastic work ratio $\left(\mathrm{u}_{\mathrm{p}}\right)$, defined as:

$$
\mathrm{u}_{\mathrm{P}}=\mathrm{W}_{\mathrm{p}} / \mathrm{W}_{\mathrm{t}}
$$

where $\mathrm{W}_{\mathrm{t}}$ is the total work of indentation which is separated intoan elastic $\left(\mathrm{W}_{\mathrm{e}}\right)$ and a plastic $\left(\mathrm{W}_{\mathrm{p}}\right.$ ) component (as seen in Fig. 1).These parameters are extracted from the experimentally measuredloading-unloading curve. Higher upvalues denote a material with a higher ability to dissipate energy in plastic deformations. Fig. 2 presents the variation of the plastic work ratio as a functionof the penetration depth. One can observe that, for both samples, the plastic work ratio is stabilized in the penetration depth inter-val $80-120 \mathrm{~nm}$. Following this interval, the 
plastic work ratio risesabruptly for the thinner sample up to a value of $\sim 0.31$. This phenomenon should be expected, considering that the penetrationdepth for this particular measurement reaches $30 \%$ of the totalfilm thickness $(500 \mathrm{~nm})$. The physics and technique of nanoinden-tation measurements in films thinner than $0.5 \mathrm{~m}$ is still a matter of debate $[19,20]$. However, considering the plastic work ratio for thesilicon substrate $(0.50)$, the fact that the measured hardness for theSiC samples is $\sim 70 \%$ higher than that of the substrate, and the sta-bilization of the plastic work ration between the penetration depth80-120 nm, the reported mechanical values for the SiC films fromTable 1 could be taken as an indication of the hardness of these verythin films. One observation that needs to be mentioned is that thevariable parameter controlled during the deposition of the samples, the number of the pulses, does not seem to significantly influenceeither the hardness or the elastic modulus.

\begin{tabular}{|c|c|c|c|c|c|c|c|c|c|}
\hline Sample & $\begin{array}{l}\text { Penetration } \\
\text { depth [nm] }\end{array}$ & $H_{\text {it }}[\mathrm{GPa}]$ & $E_{\text {it }}[\mathrm{GPa}]$ & $\begin{array}{l}\text { HV } \\
\text { Vickers }\end{array}$ & $W_{\mathrm{p}}$ & $W_{\mathrm{t}}$ & $u_{\mathrm{p}}$ & $H / E$ & $H^{3} / E^{2}$ \\
\hline \multirow{6}{*}{ SiC_17 } & 80 & 32.6 & 238 & 3023 & 20.60 & 104.83 & 0.1965 & - & - \\
\hline & 90 & 34.3 & 232 & 3176 & 27.77 & 139.01 & 0.1997 & - & - \\
\hline & 120 & 35.5 & 239 & 3290 & 62.22 & 325.96 & 0.1908 & - & - \\
\hline & 120 & 36.2 & 242 & 3351 & 68.62 & 318.95 & 0.2151 & - & - \\
\hline & Arithmetic mean value & 34.6 & 237.7 & 3210 & - & - & - & 0.14 & 0.73 \\
\hline & Relative error & $\pm 5.91 \%$ & $\pm 2.41 \%$ & $\pm 5.82 \%$ & - & - & - & - & - \\
\hline \multirow{7}{*}{ SiC_18 } & 40 & 32.7 & 261 & 3029 & 1.26 & 13.23 & 0.0952 & - & _- \\
\hline & 80 & 37.3 & 259 & 3456 & 18.25 & 119.94 & 0.1521 & - & - \\
\hline & 100 & 35.6 & 254 & 3297 & 33.52 & 204.8 & 0.1636 & - & - \\
\hline & 100 & 35.1 & 237 & 3250 & 30.58 & 184.05 & 0.1661 & - & - \\
\hline & 150 & 35.2 & 285 & 3258 & 212.71 & 697.01 & 0.3051 & - & - \\
\hline & Arithmetic mean value & 35.18 & 259.2 & 3258 & - & - & - & 0.13 & 0.64 \\
\hline & Relative error & $\pm 7.04 \%$ & $\pm 9.95 \%$ & $\pm 7.02 \%$ & - & - & - & - & - \\
\hline \multirow[t]{2}{*}{$\mathrm{Si}$ (substrate) } & Arithmetic mean value & 11.2 & 130 & 1042 & 1034.8 & 2035.0 & 0.50 & 0.08 & 0.08 \\
\hline & Relative error & $\pm 0.38 \%$ & $\pm 3.58 \%$ & $\pm 0.38 \%$ & $\pm 0.91 \%$ & $\pm 1.92 \%$ & $\pm 1 \%$ & - & - \\
\hline
\end{tabular}

From the nanoindentation obtained hardness and elastic mod-ulus it is possible to evaluate other important key parameters toanalyse the wear behavior of the films. The H/E ratio can provideinformation about the wear of the films [21], while the $\mathrm{H}^{3} / \mathrm{E}^{2}$ ratio gives information about the resistance to plastic deformation.Table 1 also contains the values for the H/E and $\mathrm{H}^{3} / \mathrm{E}^{2}$ ratios for thedeposited samples calculated using the average of the measuredvalues. One can notice that, regarding the $\mathrm{H} / \mathrm{E}$ ratio, the thicker SiCfilm (sample SiC 17) might behave slightly better during wear tests.In Table 2 , the experimentally measured values for the criticalloads concerning the adhesion to the substrate, for each track, ofeach sample, are presented. If we compare the critical load val-ues for each sample, we notice that sample SiC 18, overall, exhibitsslightly higher values, therefore a better adhesion to the substrate.Keeping in mind that the main variable while depositing the filmson the silicon substrates was the number of pulses, there seemsto be a small influence of this parameter on the adhesion to thesubstrate measurement results. During longer deposition times theentrance window transmittance decreases due to the deposition of a thin film, which in turn decreases the laser fluence incident on thetarget. Considering the values from Table 2, one could note that theadhesion of the $\mathrm{SiC}$ films to the silicon substrate is, in this particularcase, lower than that measured for the thinner film. More likely, theexplanation regarding the lower adhesion to the substrate stemsfrom the discrepancy of the mechanical characteristics of the Sisubstrate compared to the ones of the films, a typical case of a veryhard film on a soft substrate system. The mechanical characteristicsof the substrate are presented in Table 1. This observation is firstlyreinforced by the appearance of the scratch tracks.Figs. 3 and 4 represent images captured from the regionswhere the critical loads concerning the adhesion to the substratewere observed, for sample $\mathrm{SiC} 17$ and sample $\mathrm{SiC}$ 18, respectively.According to Ref. [22], the shape (chevrons) and orientation of thecracks (open to the direction of the scratch) 
from Figs. 3 and 4 arecharacteristic to the process called through-thickness cracking. Thisphenomenon is usually followed by recovery spallation (as is thecase for these particular $\mathrm{SiC}$ samples), where the coating is delam-inated due to the elastic recovery which occurs behind the stylusas it travels over the coated surface. One observation that needs tobe mentioned is that, in this particular care, the Lc3critical load isnot necessarily related to the definition (the load where more than $50 \%$ of the film is delaminated from the substrate), but representsthe cohesive failure of the thin film-substrate system, due to crack-ing occurred also in the substrate.

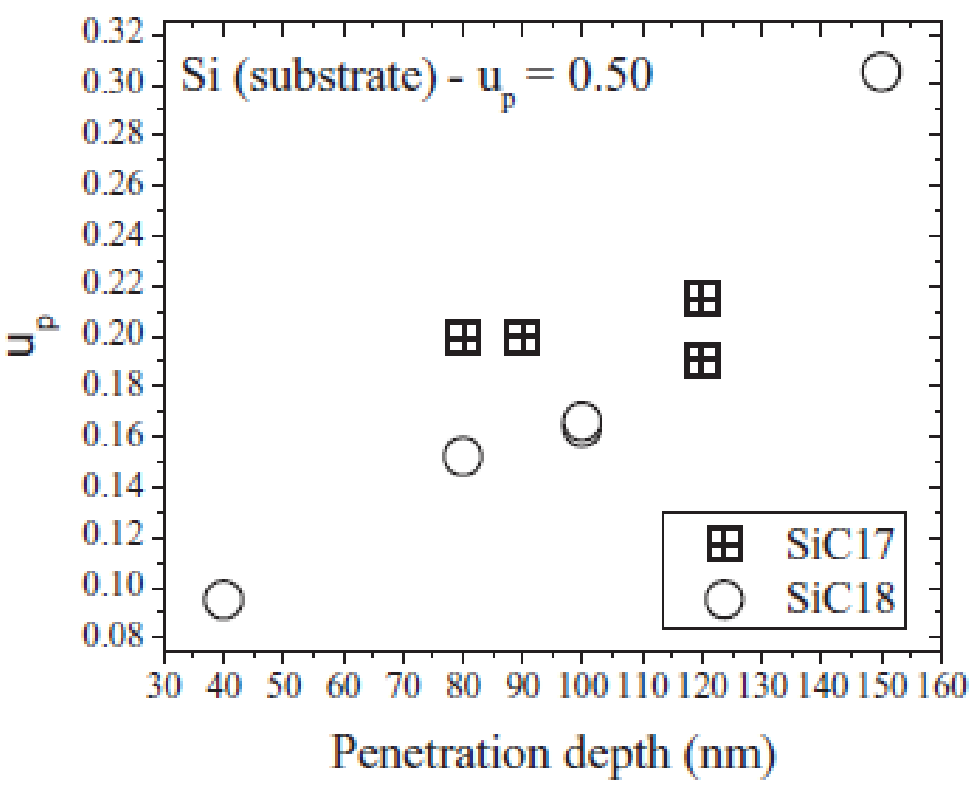

Fig. 2. The variation of the plastic work ratio as a function of the penetration depth.

Consequently, the relatively highmeasuring error for the Lc3load, in the case of sample Si 17, is notconclusive concerning the adhesion behavior, firstly due to the lackof thin film-substrate system cohesion and also accounting for thefact that past critical load Lc2the film is already considered compro-mised. Secondly, the observed critical load values were very similarto those measured for other pairs of hard film-soft substrate suchas $\mathrm{ZrC} / \mathrm{Si}$ and $\mathrm{ZrN} / \mathrm{Si}$ [23,24].

Table 2 The critical load values resulted from the adherence tests on samples $\mathrm{SiC} 17$ and $\mathrm{SiC}$ 18.

\begin{tabular}{llccc}
\hline Sample & Track & $\mathrm{LC}_{1}[\mathrm{~N}]$ & $\mathrm{LC}_{2}[\mathrm{~N}]$ & $\mathrm{LC}_{3}[\mathrm{~N}]$ \\
\hline \multirow{5}{*}{ SiC_17 } & 2.47 & 3.91 & 7.61 \\
& 2 & 2.63 & 4.64 & 5.43 \\
& 3 & 2.64 & 3.80 & 5.11 \\
& Arithmetic mean value & 2.58 & 4.11 & 6.05 \\
& Relative error & $\pm 4.26 \%$ & $\pm 12.89 \%$ & $\pm 25.78 \%$ \\
& 1 & 3.09 & 4.23 & 7.59 \\
& 2 & 2.58 & 4.32 & 7.43 \\
SiC_18 & 3 & 2.79 & 4.07 & 7.55 \\
& Arithmetic mean value & 2.82 & 4.20 & 7.52 \\
& Relative error & $\pm 8.51 \%$ & $\pm 3.09 \%$ & $\pm 1.19 \%$ \\
\hline
\end{tabular}


Examples of the recorded friction coefficients and penetrationdepths during wear tests recorded for sample $\mathrm{SiC} 17$ at room tem-perature and $900{ }^{\circ} \mathrm{C}$ are displayed in Fig. 5. The estimated valuesof the worn material as well as the wear rate for both samples aredisplayed in Table 3.The surface behavior of samples during tests is different if dif-ferent temperatures are used. In the first case (room temperature), the first part of curve shown in Fig. 5, left (1-182 s) was influencedby the inhomogeneity and roughness of the surface, the next part(plateau) being representative of the actual friction coefficient. Forthe high temperature test, even if the used $900^{\circ} \mathrm{C}$ temperature wasvery high, it is obvious that the $\mathrm{SiC} 17$ film was destroyed after asimilar length (around $17.30 \mathrm{~m}, 1.44 \mathrm{E} 03$ laps) as in the case of roomtemperature testing.The thinner SiC 18 sample exhibited a slightly higher worn vol-ume and friction coefficient average values, although the criticalloads values were higher.There are two important results from these tests: first, the fric-tion coefficients measured for these nanostructured thin $\mathrm{SiC}$ filmswere in line with other measurements reported in the literaturefor much thicker SiC films or bulk samples [25-27]. Secondly, therewere no major differences between the wear properties measuredat room temperature and those measured at $900{ }^{\circ} \mathrm{C}$. These resultsshowed that the SiC films could maintain their mechanical proper-ties at very high temperatures, making them attractive for specialapplications in nuclear reactors.

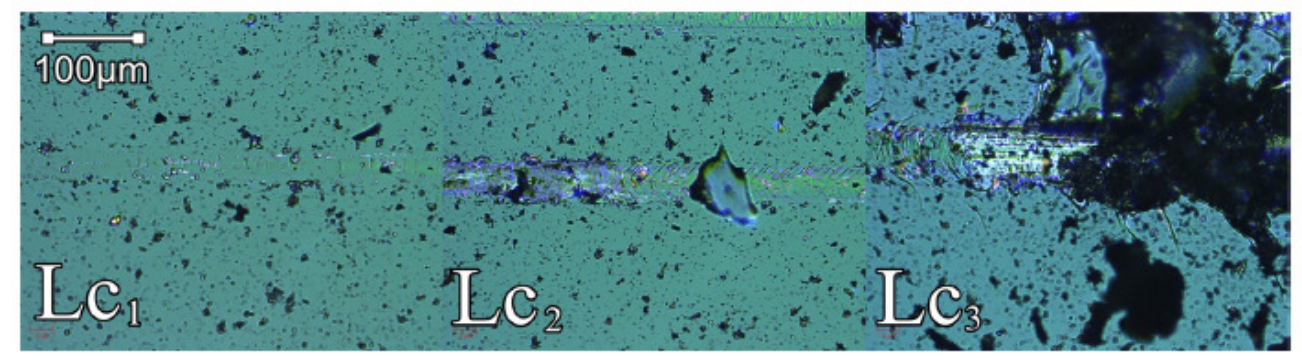

Fig. 3. Optical microscope images of the zones where the adhesion test critical loads were observed - sample SiC_17.

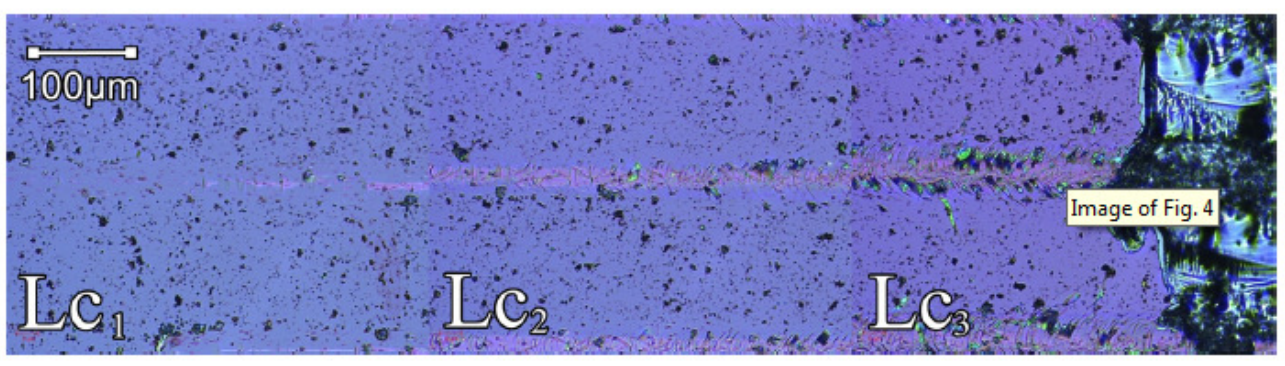

Fig. 4. Optical microscope images of the zones zones where the adhesion test critical loads were observed - sample SiC_18.

Table 3

Wear parameters recorded from $\mathrm{SiC}$ samples at room temperature and $900^{\circ} \mathrm{C}$.

\begin{tabular}{lllll}
\hline & SiC_17 & & SiC_18 \\
\hline$T,{ }^{\circ} \mathrm{C}$ & 25 & 900 & 25 & 900 \\
Worn volume $(\mathrm{V}), \mathrm{mm}^{3}$ & 0.45 & 0.32 & 0.70 & 0.35 \\
Wear rate, $\mathrm{mm}^{3} / \mathrm{m}$ & $9.99 \mathrm{E}-03$ & $7.14 \mathrm{E}-03$ & $1.54 \mathrm{E}-02$ & $7.82 \mathrm{E}-03$ \\
Coefficient of friction $(\mu)$ & 0.524 & 0.495 & 0.668 & 0.673 \\
\hline
\end{tabular}



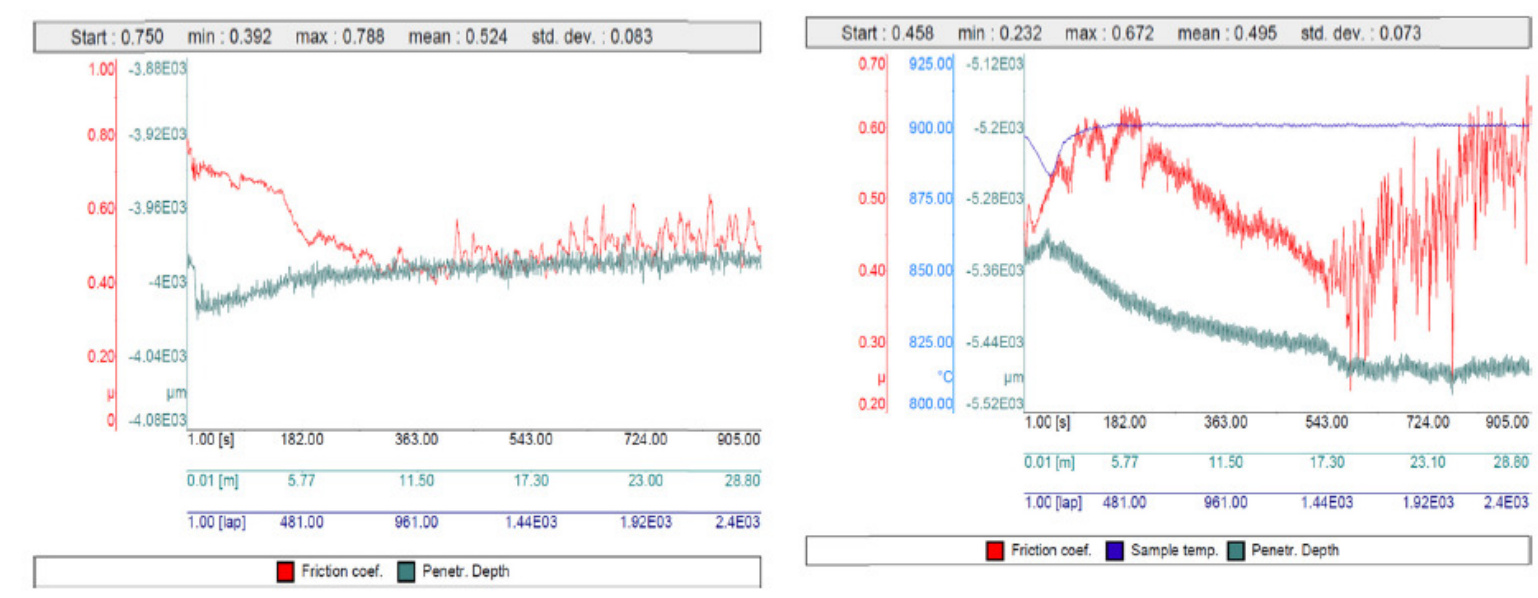

Fig. 5. Friction coefficient, penetration depth and temperature recordings during wear tests performed on Si_17 sample under air ambient at room temperature (left) and $900^{\circ} \mathrm{C}$ (right).
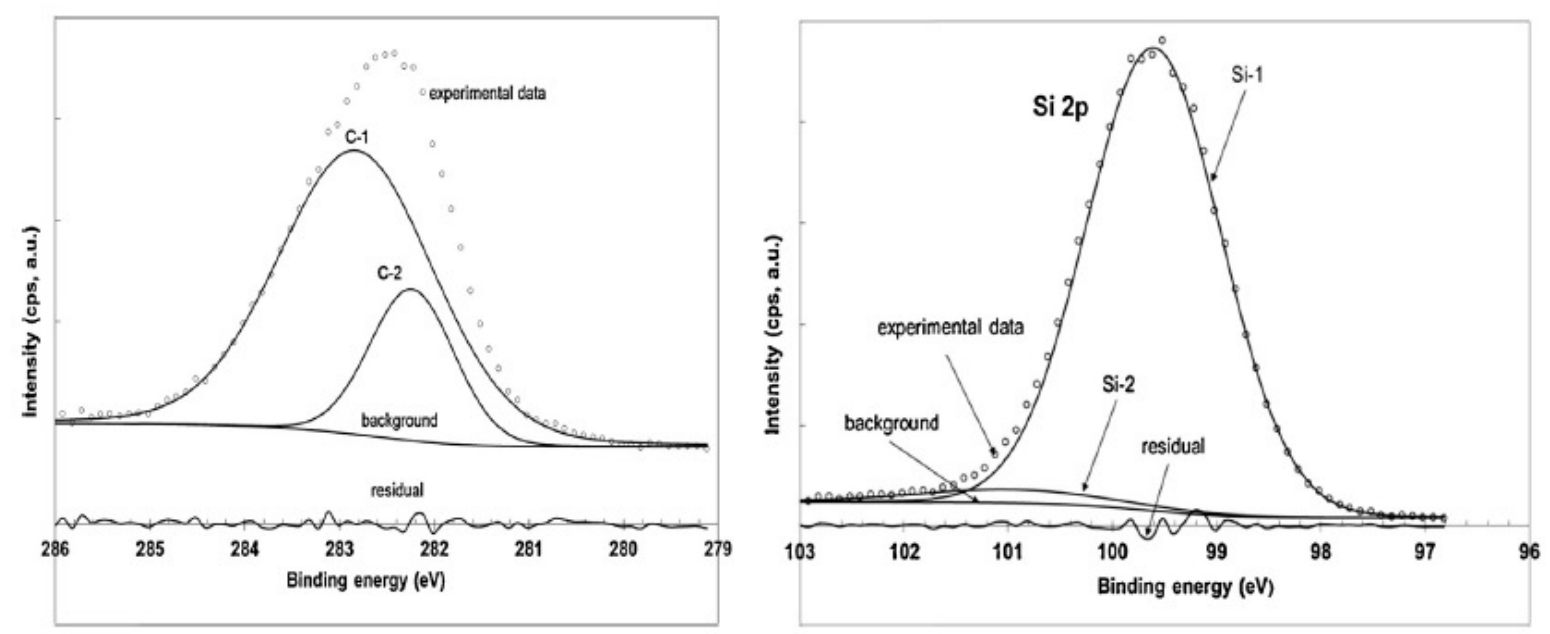

Fig. 6. Simulations of the of $\mathrm{C} 1 \mathrm{~s}$ and $\mathrm{Si} 2 \mathrm{p}$ high resolution XPS core levels spectra acquired from bulk.

The good wear results could be explained by the results of theanalysis of high resolution XPS scans of the C 1 s and Si $2 p$ regionsacquired from bulk and displayed in Fig. 6. The Si peak was fittedwith one high intensity peak located at $99.79 \mathrm{eV}$, which correspondto $\mathrm{Si}-\mathrm{C}$ bonds $[1,28,29]$ and a very small peak, representing around $2 \%$ of the large peak area and located at $100.67 \mathrm{eV}$, most likelyindicative of a Si carboxide compound, since the binding energy(BE) is significantly lower than the $\sim 103 \mathrm{eV}$ value correspondingto $\mathrm{Si}$ in $\mathrm{SiO} 2[1,28,29]$. However, at least two peaks of similar areas,corresponding to two chemical bonds for $\mathrm{C}$ atoms were necessary toobtain a good fit of the acquired slightly asymmetric $\mathrm{C} 1 \mathrm{~s}$ peak. Thelower BE of the second smaller area peak was located at 282.31 eVand should correspond to C-Si bonds $[1,28,29]$. It also showed a sig-nificantly smaller FWHM value than the higher BE peak, indicativeof better order in this type of compound. The higher BE peak, locatedat 283.04, which is also wider, must include some contribution fromC-C bonds. It is an indication that the deposited $\mathrm{SiC}$ films containsa mixture of two regions, one being more ordered and mainly con-taining $\mathrm{Si}-\mathrm{C}$ bonds and a more disordered one, also containing afraction of $\mathrm{C}-\mathrm{C}$ bonds. Some fraction of this disordered layer mayalso be a partial result of the long duration Ar ion sputtering of thesample during XPS analysis.4. ConclusionsThe mechanical properties of dense and nanocrystalline SiCfilms grown at $1000^{\circ} \mathrm{C}$ by the PLD technique on Si substrates 
usinga high laser fluence, high repetition rate and high purity atmo-sphere conditions were investigated. Nanoindentation and scratchtest results found that the SiC films were very hard and adherentto the Si substrate, while wear tests showed that films exhibitedat $900^{\circ} \mathrm{C}$ similar friction coefficients and wear rates to those mea-sured at room temperature. The presence of $\mathrm{C}-\mathrm{C}$ bonds within thebulk, detected by XPS investigations, could account for the goodwear behavior. These results show that such $\mathrm{SiC}$ films could be suc-cessfully used in demanding high temperature applications such asnuclear fuel encapsulation.

\section{Acknowledgements}

This work was supported by the IFA-CEA C3-03 grant, UEFIS-CDI Romanian-Hungary bilateral agreement and CNCS - UEFISCDIproject Nucleu 2014.

\section{References}

[1] P.R. Poudel, P.P. Poudel, B. Rout, M. El Bouanani, F.D. McDaniel, Nuclear Instru-ments and Methods in Physics Research Section B: Beam Interactions withMaterials and Atoms 283 (July) (2012) 93-96.

[2] C. Ricciardi, G. Fanchini, P. Mandracci, Diamond and Related Materials 12 (2003)12361240 .

[3] Y.Y. Wang, K. Kusumoto, C.J. Li, Physics Procedia 32 (2012) 95-102.

[4] J.C. Oh, E. Yun, M.G. Golkovski, S. Lee, Materials Science and Engineering A 351(2003) 98-108.

[5] Q.B. Ma, J. Ziegler, B. Kaiser, D. Fertig, W. Calvet, E. Murugasen, W. Jaegermann,International Journal of Hydrogen Energy 39 (2014) 1623-1629.

[6] M. Ollivier, L. Latu-Romain, M. Martin, S. David, A. Mantoux, E. Bano, V. Souliere,G. Ferro, T. Baron, Journal of Crystal Growth 363 (2013) 158-163.

[7] J. Wang, b. Liu, Y.L. Shao, Z.M. Lu, M.L. Liu, Nuclear Engineering and Design 271(2014) 162-165.

[8] A. Udayakumar, M. Stalin, K. Venkateswarlu, Surface and Coatings Technology219 (2014) 76.

[9] H. Muto, T. Asano, R.P. Wang, T. Kusumori, Applied Physics Letters 87 (2005)(article number: 162106).

[10] I. Hanyecz, J. Budai, A. Oszkó, E. Szilágyi, Z. Tóth, Applied Physics A 100 (2010)1115-1121.

[11] Y.S. Katharria, S. Kumar, R.J. Choudhary, R. Prakash, F. Singh, N.P. Lalla, D.M.Phase, D. Kanjilal, Thin Solid Films 516 (2008) 6083-6087. 
[12] A.M. Reinecke, M. Lustfeld, W. Lippmann, A. Hurtado, Nuclear Engineering andDesign 271 (2014) 92-98.

[13] V. Craciun, E. Lambers, N.D. Bassim, R.H. Baney, R.K. Singh, Journal ofVacuum Science \& Technology A: Vacuum Surface and Films 19 (2001)2691-2694.

[14] G. Monaco, M. Suman, D. Garoli, M.G. Pelizzo, P. Nicolosi, Journal of ElectronSpectroscopy and Related Phenomena 184 (2011) 240-244.

[15] G. Socol, A.C. Galca, D. Craciun, M. Hanna, C.R. Taylor, E. Lambers, V. Craciun,Applied Surface Science 306 (2014) 66-69.

[16] W.C. Oliver, G.M. Pharr, Journal of Materials Research 47 (1992) 1564-1583.

[17] P. Du, X.N. Wang, I.K. Lin, X. Zhang, Sensors and Actuators A: Physical 176 (2012)9098.

[18] A.V. Singh, S. Chandra, S. Kumar, G. Bose, Journal of Micromechanics and Microengineering 22 (2012) (article number: 025010).

[19] Seung Min Han, R. Saha, W.D. Nix, Acta Materialia 54 (April (6)) (2006)1571-1581.

[20] M. Cabibbo, S. Spigarelli, Physics Procedia 40 (2013) 1-8.

[21] T.L. Oberle, Journal of Metals 3 (1951) 438.

[22] S.J. Bull, Surface and Coatings Technology 50 (1991) 25-32.

[23] G. Dorcioman, G. Socol, D. Craciun, N. Argibay, E. Lambers, M. Hanna, C.R. Taylor,V. Craciun, Applied Surface Science 306 (1 July) (2014) 33-36.

[24] V. Craciun, E. McCumiskey, M. Hanna, C.R. Taylor, Journal of the EuropeanCeramic Society 33 (2013) 2223-2226.

[25] Pavol Kurek, Ján Balko, Ján Dusza, Pavol`Sajgalík, Mária Mihaliková, Interna-tional Journal of Refractory Metals and Hard Materials 44 (2014) 12-18.

[26] Hanqin Liang, Xiumin Yao, Hui Zhang, Xuejian Liu, Zhengren Huang, Interna-tional Journal of Refractory Metals and Hard Materials 44 (2014) 12-18.

[27] V. Kulikovsky, V. Vorlicek, R. Ctvrtlik, P. Bohac, J. Suchanek, O. Blahova, L. Jastrabik, Surface \& Coatings Technology 205 (2011) 3372-3377.

[28] Y. Matsuda, S.W. King, R.H. Dauskardt, Thin Solid Films 531 (2013) 552-558.

[29] S. Cichon, P. Machác, B. Barda, M. Kudrnová, Microelectronic Engineering 106(2013) $132-138$. 